\title{
Long Term Monitoring of Ghana's Forest Reserves Using Google Earth Engine
}

\author{
Jeff Dacosta Osei \\ Supervised By: Dr. S. A. Andam-Akorful * and Dr. Edward Matthew Osei Jnr * \\ Affiliation: Kwame Nkrumah University of Science and Technology (KNUST) \\ Correspondence: akorful@gmail.com (S. A. Andam-Akorful); emosei.coe@knust.edu.gh
}

(Edward Matthew Osei Jnr)

\begin{abstract}
Farm activities, continued sand winning operations and the allocation of plots of land to prospective developers in Ghana pose a serious threat to the forest covers and lifespan of the Forest and game reserves. With all the positive add ups to the country from forests, Ghana has lost more than 33.7\%(equivalent to 2,500,000 hectares) of its forest, since the early 1990s between 2005 and 2010 (GNA, 2017),the rate of deforestation in Ghana was estimated at $2.19 \%$ per annum; the sixth highest deforestation rate globally for that period (GNA, 2017). This shows how important forest monitoring can be to the forestry commission in Ghana. Despite the frameworks which have been developed to help Ghana to protect and restore its forest resources, inadequate monitoring systems remain a barrier to effective implementation (GNA, 2017). In this study, Google earth engine was used to map and analyse the structural changes of forest cover using Java Script to query and compute Landsat, MODIS and NOAA AVHRR satellite imageries of the study area (Ghana) with spatial resolutions $30 \mathrm{~m}, 250 \mathrm{~m}$ and $7 \mathrm{~km}$ respectively. A supervised classification was performed on three multi-temporal satellite imageries and a total of six major land use and land cover classes were identified and mapped. By using random Forest-classification technique, from 1985 to 2018 recorded by NOAA AVHRR, forest cover has decreased by $66 \%$ and 2000 to 2018 recorded by Landsat and MODIS 61\% and $47 \%$ respectively. Decrease in forest has been as a result of anthropogenic activities in Ghana. A change detection analysis was performed on these images and it was noted that Ghana is losing forest reserves in every 5years. Overlay of the reserved forest of the 2000 and the classified map of 2018 shows vegetation changed during 2000-2018 remarkably. Therefore, forest related institutions like the Forestry Commission can employ and use
\end{abstract}


this monitoring system on Google Earth Engine for processing satellite images particularly Landsat, MODIS and NOAA AVHRR for forest cover monitoring and analysis for fast, efficient and reliable results.

\section{Keywords}

land cover; classification Spatial and temporal Analysis; forest cover; Google Earth Engine (GEE); MODIS; Landsat; NOAA AVHRR

\section{Introduction}

Until recent years, forest cover monitoring was a very difficult task to accomplish given the amount of time and resources needed to map and update records. Conventional ground surveys were used to gather forest data inventories by measuring variables in permanent plots such as diameter at breast height (dbh), tree height, percentage of canopy cover, number of trees and tree species. Such surveys covered very small areas and are usually costly, time-consuming, tedious, and plagued with logistical difficulties in the tropics (Paneque-Gálvez, et al, 2014). Huge amounts of data were also collected from the field using aerial photographs which is not the best method for the prediction and analysis of forest cover.

GPS navigation, orientation and map update for the forest change analysis remain core challenges in the remote sensing world. As a result of technological and research advancement, satellite images with high resolutions are now used for this task to improve the efficiency of forest mapping and change detection. Introduction of Google Earth Engine has made Remote Sensing more exciting and easier. The processing of remote sensing data has now become faster and more efficient as compared to previous techniques used for this same purpose. A team led by University of Maryland's Matt Hansen used Earth Engine to survey over a decade of global tree cover extent, loss, and gain. What would have taken a single computer 15 years to perform was completed in a matter of days using Google Earth Engine (GEE) computing (Schabrun, 2017). Google Earth Engine has made it possible for the first time in history to rapidly and accurately process vast amount of satellite imagery, identifying where and when tree cover change has occurred at high resolution. Global Forest Watch would not exist without GEE (Schabrun, 2017). To this effect, forest in Ghana can now be monitored easily for the country to benefit from its functions. 
Ghana's forest definition in the context of REDD+ (Reducing from Deforestation and Forest Degradation) is 15\% canopy cover, 5 meters tall, and 1 hectare in area, based on thresholds set by the Intergovernmental Panel on Climatic Change for these structural parameters and the Marrakesh Accord. Forested areas, forest patches, or assemblages of naturally regenerated tree that have at least 15\% canopy cover, with an average height of 5 meters, and cover a minimum area of 1 hectare constitute a forest for the purposes of REDD+ in Ghana. Forest monitoring is defined by the International Union of Forest Research Organizations (IUFRO) as the regular and periodic measurement of certain parameters of forests (physical, chemical, and biological) to determine baselines to detect and observe changes over time (Atlas, 2017). Food and Agriculture Organization (FAO) stated that forest cover four billion hectares (15 million square miles) or approximately $30 \%$ of the world's area in 2006 ('Environment program', 2010). In Ghana, forest cover about one - third of the country's total area, with commercial forestry concentrated in the southern parts of Ghana.

The existence of forest is very vital in every country as the country benefits in so many ways from it. Humanity depends on forest for survival; respiration, feeding, wood for domestic and industrial purposes, all would not have been possible without forest. Forest also serve as a habitat for animals and livelihoods for humans. Forest mitigates climate change and prevent erosion. With all the positive add ups to the country from forest, Ghana has lost more than 33.7\%(equivalent to 2,500,000 hectares) of its forest, since the early 1990s between 2005 and 2010 (GNA, 2017). The rate of deforestation in Ghana was estimated at $2.19 \%$ per annum; the sixth highest deforestation rate globally for that period (GNA, 2017). This shows how important forest monitoring can be to the forestry commission in Ghana. Despite the frameworks which have been developed to help Ghana to protect and restore its forest resources, inadequate monitoring systems remain a barrier to effective implementation (GNA, 2017).

Satellite data have become a major application in forest change detection because of the repetitive coverage of the satellites at short intervals (Kennedy et al., 2009). Satellite data can be used to generate earth's surface elevation, determine land use change over particular years, disaster mitigation planning and recovery, monitoring draught, monitoring air pollution. Spatial and temporal Analysis was performed on a supervised image showing forest cover map of Ghana within 5years interval to perform forest cover change detection maps of Ghana for MODIS, Landsat and NOAA AVHRR. The process will produce yearly composite maps from 1985 to 2018 which can be used for forest 
monitoring. The Forestry Commission of Ghana as a key institution when it comes to forest monitoring and management uses satellite images to determine the changes in the forest cover of Ghana. This helps the institution to estimate and predict forest loss and gains over a number of years.

The existence of clouds on some satellite images especially images of the Southern part of the country where there is majority of the national forest makes their usage not appropriate. Notwithstanding, the storage required to store and process such large amounts of spatial data and update the forest maps yearly, desktop computers cannot be used in processing of such huge amount of data. The Forestry Commission of Ghana would therefore need more storage in updating the forest maps which can make orientation and GPS navigation on the maps inconsistent to corroborate how the country is losing or gaining forest covers over the years, hence the need of a more advanced and fast technology for processing the satellite images for good productivity would be a suitable remedy for this challenge as technology and research advance. The aim of this research is to produce a Google Earth Engine long term forest cover monitoring system of Ghana to investigate spatial and temporal patterns in forest reserves.

Several studies on forest cover change and monitoring have been done by individuals and group of researchers. Examples of which include (Hansen et al, 2013) and (Desclée, Bogaert, \& Defourny, 2006).With the Hansen et al, 2013, Landsat images with spatial resolution of $30 \mathrm{~m}$ were used and the Supervised classification process was employed in classifying the images to produce a Global Forest Cover change map.

A similar project was also done on African forest and land cover change by another group of researchers who using Landsat MSS/TM Satellite Image Data over West Africa between 1975 and 1990 Marian. This study examined land cover changes occurring between 1975 and 1990 in West Africa using a systematic sample of satellite imagery. The primary data sources for the land cover classification were Landsat Multispectral Scanner (MSS) for 1975 and Landsat Thematic Mapper (TM) for the 1990 period. Dedicated selection of the appropriate image data for land cover change monitoring was performed for the year 1975. Based on this selected dataset, the land cover analysis was done on a systematic sample of 220 suitable Landsat image extracts (out of 246) of $20 \mathrm{~km} \times 20 \mathrm{~km}$ at each one-degree latitude/longitude intersection. Object-based classification, originally dedicated for Landsat TM land cover change monitoring and adapted for MSS, was used to produce land cover change information for four different land cover classes: dense tree 
cover, tree cover mosaic, other wooded land and other vegetation cover(Vittek et al., 2013).

Another project, Nominal 30-m Cropland Extent Map of Continental Africa was done by Integrating Pixel-Based and Object-Based Algorithms Using Sentinel-2 and Landsat-8 Data on Google Earth Engine. In this project, researchers presented an approach for cropland extent mapping at high spatial resolution (30-m) using the 10-day, 10 to 20-m, Sentinel-2 data in combination with 16-day, 30-m, Landsat-8 data on Google Earth Engine (GEE). First, nominal 30-m resolution satellite imagery composites were created from 36,924 scenes of Sentinel-2 and Landsat-8 images for the entire African continent in 20152016. These composites were generated using a median-mosaic of five bands (blue, green, red, near-infrared, NDVI) during each of the two periods (period 1: January-June 2016 and period 2: July-December 2015) plus a 30-m slope layer derived from the Shuttle Radar Topographic Mission (SRTM) elevation dataset. Second, they selected Cropland/Non-cropland training samples (sample size $=9791$ ) from various sources in GEE to create pixel-based and object-based classifications to identify the cropland and no-croplands in Africa.

Ghana has also had a number of researchers undertaking projects on forest cover monitoring. Examples of these project include Classification and Ecology of ClosedCanopy Forest in Ghana. In this project, available global mangrove databases were compiled using disparate geospatial data sources and national statistics, need to be improved. Researchers mapped the status and distributions of global mangroves using recently available Global Land Survey (GLS) data and the Landsat archive. Again, interpretations of approximately 1000 Landsat scenes were made using hybrid supervised and unsupervised digital image classification techniques. Each image was normalized for variation in solar angle and earth-sun distance by converting the digital number values to the top-of-the-atmosphere reflectance. Ground truth data and existing maps and databases were used to select training samples and also for iterative labelling. Results were validated using existing GIS data and the published literature to map 'true mangroves' (Swaine, 2015). Another project, Analysis of Forest Cover Change Detection was done to map out and analyse the structural changes of forest cover using Landsat and ASTER imageries.

A supervised classification was performed on three multi-temporal satellite imageries and a total of eight major land use and land cover (LULC) classes were identified and 
mapped. By using post-classification techniques, from 1986 to 2002 and 2002 to 2007, it was noted that the forest cover has decreased by an amount of 2136.6 ha and 1231.56 ha respectively representing $24.7 \%$ and $14.2 \%$. Generally, the results indicated that from 1986 to 2007, forest cover had reduced by 3368.16 ha, representing 38.9\%. Decrease in vegetation has been as a result of anthropogenic activities in the study area. An NDVI analysis was performed on these images and it was noted that there was no significant difference between the NDVI classification and the supervised classification of the images. Overlay of the reserved forest of the 1974 and the classified map of 2007 shows vegetation changed during 1986-2007 remarkably (Forkuo \& Frimpong, 2012).

From the above projects of forest cover change done for the whole world, Africa and Ghana, all used remote sensing techniques to process satellite images to produce their final forest cover maps. On the other hand, ground surveying techniques are time consuming and expensive to monitor forest at the global, Africa and Ghana scale.

\section{Research Area, Materials and Methods}

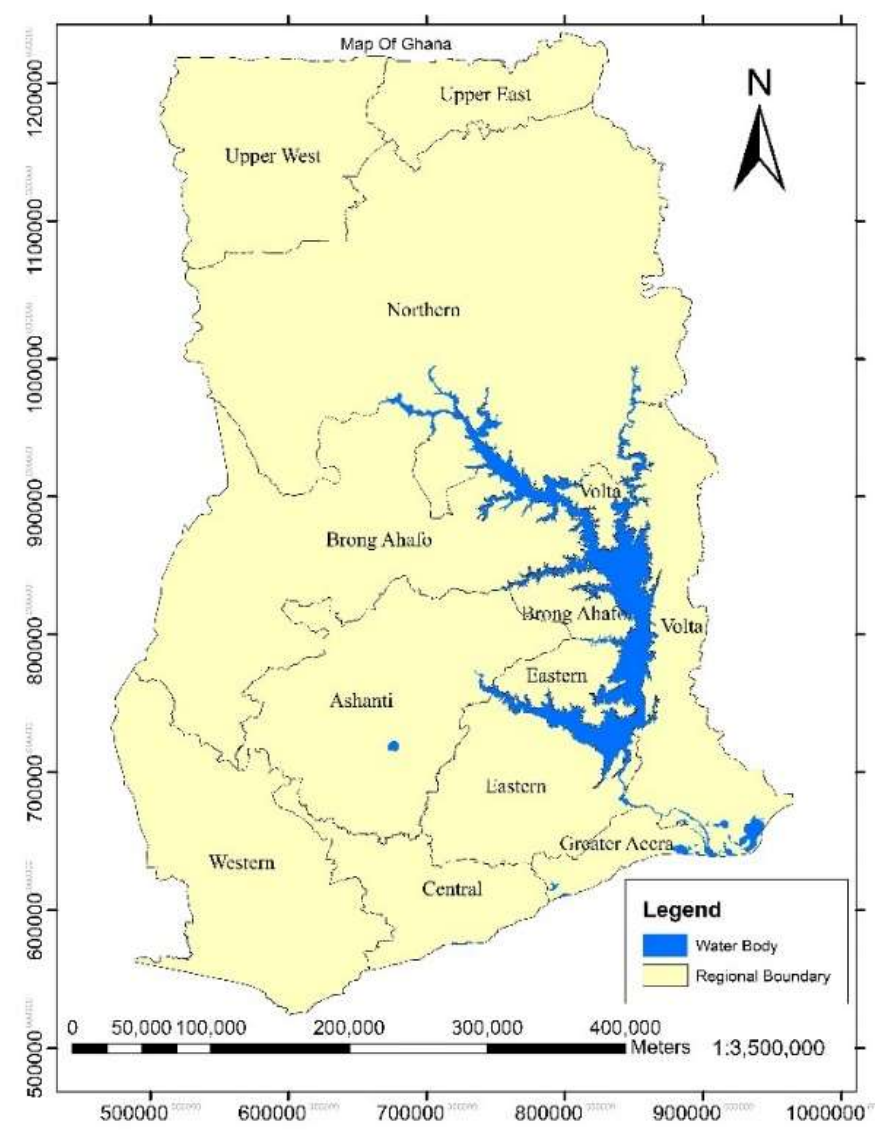

Figure 1. Study Area 


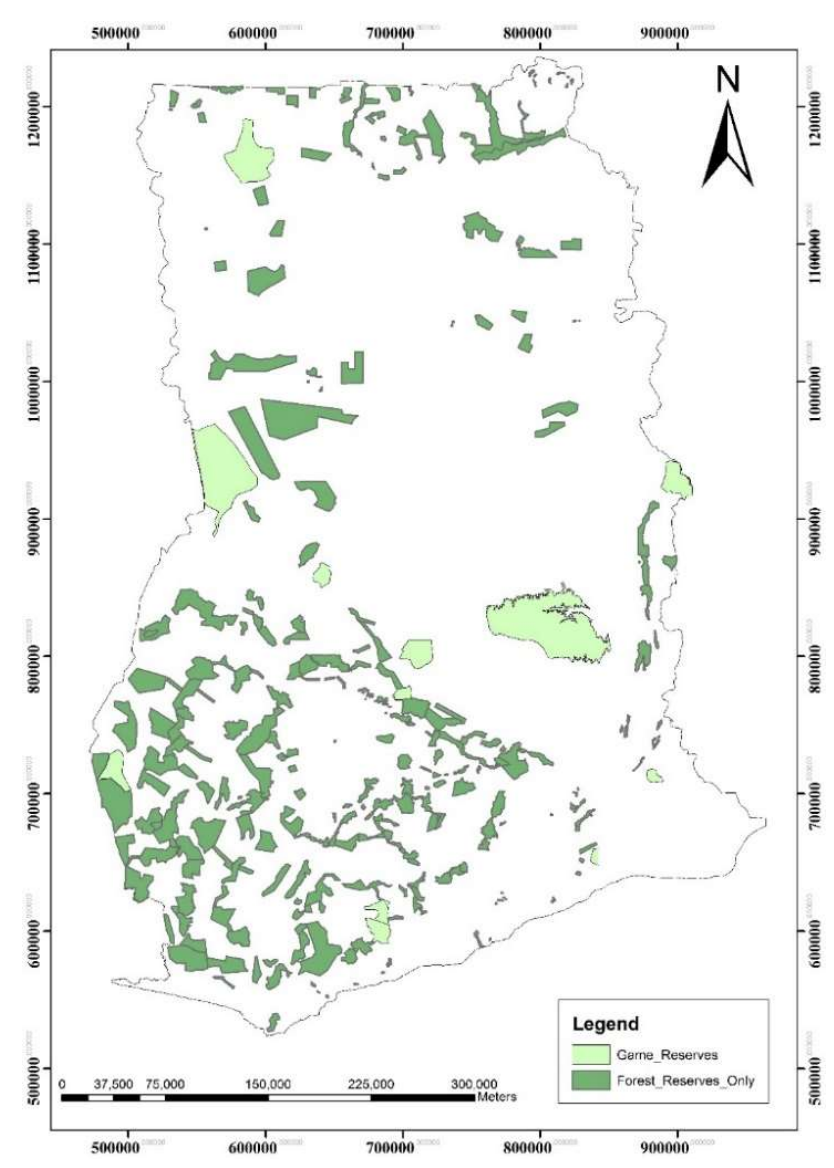

Figure 2. Forest and Game reserves shape file

The study area is Ghana, which lies in the center of the Gulf of Guinea coast, $2420 \mathrm{~km}$ of land borders with three countries: Burkina Faso $(602 \mathrm{~km})$ to the north, Ivory Coast $(720$ $\mathrm{km})$ to the west and Togo $(1,098 \mathrm{~km})$ to the east. To the south are the Gulf of Guinea and Atlantic Ocean.

It is located on latitude $7.9465^{\circ} \mathrm{N}$ and longitude $1.0232^{\circ} \mathrm{W}$ and covers $238,536 \mathrm{~km}^{2}$. The highest point is the Mount Afadjato which is one of the highest mountains in Ghana at an elevation of 885 meters (2904ft). The Greenwich Meridian, which passes through London, also traverse the eastern part of Ghana at Tema. Half of the country lies less than 152 meters (499 ft.) above sea level and the highest point is 833 meters $(2,897 \mathrm{ft})$ as shown in Fig. 1.

\section{Dataset}


Satellite images used in this research were all retrieved from the Google Earth Engine server where different datasets are available and could be freely accessed. For this project, the satellite images used were MODIS, NOAA AVHRR, Landsat 7 and 8 . The shape files for pre-processing were obtained from the Forestry Commission with required attributes and spatial reference as shown in Fig.2. Google Earth engine API (cloud platform) and ArcGIS ArcMap 10.3 desktop application.

\begin{tabular}{|l|l|l|l|}
\hline Satellite Mission & Spatial resolution & Temporal Resolution & Time span \\
\hline Landsat7 & $30 \mathrm{~m}$ & $1 \mathrm{yr}$ & $1999-2014$ \\
\hline Landsat8 & $30 \mathrm{~m}$ & $1 \mathrm{yr}$ & $20013-2018$ \\
\hline MODIS & $250 \mathrm{~m}$ & 8 days & $2000-2018$ \\
\hline NOAA AVHRR & $7 \mathrm{~km}$ & 1 day & $1981-2018$ \\
\hline
\end{tabular}

\section{Image Pre-processing}

The various methods employed at this stage include Compositing or Mosaicking, Clipping and Cloud Sorting.

\section{Compositing / Mosaicking}

In general, compositing refers to the process combining spatially overlapping images into a single image based on an aggregation function. Mosaicking refers to the process of spatially assembling image datasets to produce a spatially continuous image. In Google Earth Engine, these terms are used interchangeably, though both compositing and mosaicking are supported (Engine, 2017).The satellite images were acquired in the form of images covering limited areas in path and rows. A JavaScript code was engineered using Google Earth Engine to assemble all the images covering Ghana which produced a spatially continuous image. The process produced an Earth Engine image collection for the area of study. An image collection refers to a set of Earth Engine images. For example, the collection of all Landsat 8 images is an earth engine image collection. Like the SRTM image or DEM, image collections also have an ID. As with single images, you can discover the ID of an image collection by searching the Earth Engine data catalogue.

\section{Clipping}


Clipping is the process where by an image or image collection in the earth engine is subset according to defined boundaries or the boundary of a shape file. Clipping reshaped the image to match the area of interest. The JavaScript codes in Earth engine were employed in retrieving the image and loading the shape file by converting it into a fusion table. The fusion table contains the parameters for the geometry of the shape file to sort the image to the area of interest.

\section{Cloud Sorting}

This process removes cloud-contaminated portions of a satellite image and then reconstructs the information of missing data utilizing temporal correlation of multitemporal images (Lin, Tsai, Lai, \& Chen, 2013). This algorithm is programmed in a Google Earth Engine using JavaScript function to clone information from cloud-free patches to their corresponding cloud-contaminated patches. This process is done under the assumption that land covers change insignificantly over a short period of time. It is then mathematically formulated as a Poisson equation and solved using a global optimization process. The process will remove or reduced cloud cover of satellite images to less than $5 \%$.

\section{Classification}

An unsupervised classification of three satellite images (MODIS, Landsat and NOAA AVHRR) was used to produce six classes. Random Forest classification technique was performed using all spectral band in each satellite image. This is the most recent adopted classification algorithm. 70\% of the training data (signatures) shown in Fig3.4 are used for supervised classification and $30 \%$ is use to validate the outcome of the supervised image. Using both supervised and unsupervised classification, the classified images are then compared using the validation overall accuracy which is the accuracy assessment of the classified image. The system is made to accept a validation overall accuracy greater than $65 \%$ for process continuations or start the classification process all over again with different signatures when validation accuracy is less than $65 \%$. The process continues to yield final supervised maps of Ghana showing the various forest covers for spatial and temporal analysis.

\section{Unsupervised classification (Clustering)}

Unsupervised classification (commonly referred to as clustering) is an effective method of partitioning remote sensor image data in multispectral feature space and extracting land-cover information. This project used the K-mean algorithm for the unsupervised classification. 


\section{K-Mean Algorithm}

This is an unsupervised algorithm that tries to cluster data based on their similarity. Initially the algorithm assigns each data to a cluster randomly and finds the centroid of each cluster (Ri, Xvlqj, \& Ojrulwkp, 2016). Then algorithm executes the following steps in iteration

- Reassign data points to the cluster whose centroid is closer

- Calculate new centroid of each cluster

These two steps keep on executing till the intra class variation cannot be reduce any further by a great deal. The intra cluster variation is calculated as the sum of the Euclidean distance between the data points and their respective cluster centroids. An unsupervised classification using the

$\mathrm{K}$-mean was performed using the earth engine API with Java Script codes to retrieve and execute the composite of Ghana using six (6) clusters

\section{Supervised Classification Algorithm (Random Forest)}

Random forest is a classification and regression algorithm originally designed for the machine learning community. This algorithm is increasingly being applied to satellite and aerial image classification and the creation of continuous fields data sets, such as, percent tree cover and biomass (Horning, 2010). Random forests have several advantages when compared with other image classification methods. It is non-parametric, capable of using continuous and categorical data sets, easy to parametrize, not sensitive to overfitting, good at dealing with outliers in training data, and it calculates ancillary information such as classification error and variable importance (Debreuve \& Morpheme, n.d.).

In recent years a number of algorithms developed for machine learning have been adopted for remote sensing applications. These include neural networks, support vector machines, boosting, and random forests. Traditionally, remote sensing classification methods rely on statistical models to determine how radiance values recorded by a sensor should be grouped into a number of categories or classes (e.g., land cover type). These statistical approaches work on the assumption that an appropriate data model is being used and parameters for the model can be approximated from the data (Elith \& Leathwick, 2009) .For example, when using the maximum likelihood classifier, the model assumes that the image data for each class and therefore the training data used to parameterize the model are normally distributed. A machine learning approach, on the 
other hand, does not start with a data model but instead learns the relationship between predictor and response data (Breiman, 2001).

By removing the need for data to fit a specific model, machine learning algorithms offer the opportunity to incorporate a diverse variety of data layers in addition to image data (e.g., digital elevation models, soil type, and climate data) into the classification algorithm. A number of papers reported the use of a combination of multiple classifiers to produce a single classification in the remote sensing literature( $\mathrm{Li}, \mathrm{Zou}, \mathrm{Hu}, \mathrm{Wu}, \& \mathrm{Yu}$, 2013).The resulting classifier, referred to as an ensemble classifier, is generally found to be more accurate than any of the individual classifiers making up the ensemble (Dietterich, 2002). An ensemble classifier combines the decision of a set of classifiers by weighted or unweighted voting to classify unknown examples. Studies using boosting (Freund and Schapire, 1996) with a decision tree as a base classifier have reported significant increase in classification accuracy for land cover classification studies (Friedl et al., 1999; Muchoney et.al., 2000; Pal and Mather, 2003a). Google Earth engine has programmed this algorithm on their API which uses machine learning to classify available satellite images, the random forest classifier as proposed by Breiman (1999).

This classifier involves in choosing a set of features randomly and creating a classifier with a bootstrapped sample of the training data. A large number of trees (classifiers) are generated in this way and finally unweighted voting is used to assign an unknown pixel to a class. Further, the performance of the random forest classifier is compared with support vector machines in term of classification accuracy, training time and user-defined parameters.

\section{Advantages of Random Forest}

Random Forest classifier has advantages over other classifiers. Some of these advantages are:

- It is unexcelled in accuracy among current algorithms

- It runs efficiently on large data bases.

- It can handle thousands of input variables without variable deletion.

- It gives estimates of what variables are important in the classification.

- It has an effective method for estimating missing data and maintains accuracy when a large proportion of the data are missing.

\section{Validation}


In the study, the classification accuracy is assessed by an error matrix. This is a square array of numbers organized in rows and columns which expresses the number of sample units (i.e. pixels and clusters of pixels) assigned to a particular category relative to the actual category as indicated by reference data (Forkuo \& Frimpong, 2012). Many measurements have been proposed to improve the interpretation of the error matrix, among which the Kappa coefficient is one of the most popular measures. It is a discrete multivariate technique used in accuracy assessment. The Kappa coefficient represents the proportion of agreement obtained after removing the proportion of agreement that could be expected to occur by chance.

Kappa coefficient is widely used because all elements in the classification error matrix, and not just the main diagonal, contribute to its calculation and because it compensates for change agreement. The Kappa coefficient lies typically on a scale between 0 (no reduction in error) and 1 (complete reduction of error). The latter indicates complete agreement and is often multiplied by 100 to give a percentage measure of classification accuracy. Kappa values are also characterized into 3 groupings: a value greater than 0.80 (80\%) represents strong agreement, a value between 0.40 and 0.80 (40 to 80\%) represents moderate agreement, and a value below 0.40 (40\%) represents poor agreement. Kappa can be used as a measure of agreement between model predictions and reality or to determine if the values contained in an error matrix represent a result significantly better than random. Kappa according to this project is computed using JavaScript overall accuracy code in earth engine. The accuracy and kappa statistics as shown in Table 2 as computed on the Google earth engine.

\section{Spatial and Temporal analysis}

Spatial and temporal Analysis is performed on the supervised classified forest cover map of Ghana using epoch of 5years to produce Forest cover change detection maps of Ghana for the MODIS, Landsat and NOAA AVHRR. The process also produces clipped forest and game reserves for spatial and temporal analysis by performing image differencing where one image is subtracted from the other. The resultant image after differencing is reclassified with DN(digital number) 0 as no change, 1 as gain and -1 as loss using earth engine JavaScript code. This process is done on the Google earth engine platform where the second dataset which is a median composite for one year that has undergone preprocessing and classification is subtracted from first dataset to produce a new composite that shows properties of loss and gain or no change. The new composite called the change composite would be reclassify to set all loss to a value of -1 , gain to 1 and no change to 0 . 
This is done using JavaScript codes for spatial analysis on Google earth engine. The palettes are change to red, green and yellow for loss, gain and no change respectively.

\section{System Results and Discussions}

Based on objectives and research questions, the following results were obtained from the project execution; a forest cover map of Ghana for spatial and temporal analysis has been produced from the Google Earth Engine Platform and has yielded very positive results to its quest to achieve the set down objectives. This forest cover, spatial and temporal analysis map of Ghana clearly shows the gains and losses of the various forest and game reserves in Ghana. This map is structured into Four (4) parts as shown in Table 1.

Table 1. Map Composites

\begin{tabular}{|l|l|l|}
\hline Satellite Mission & Available Maps & Range \\
\hline Landsat7 & $\begin{array}{l}\text { Forest cover yearly composite maps, spatial and } \\
\text { temporal analysis maps of Ghana }\end{array}$ & $1999-2014$ \\
\hline Landsat 8 & $\begin{array}{l}\text { Forest cover yearly composite maps, spatial and } \\
\text { temporal analysis maps of Ghana }\end{array}$ & $2013-2018$ \\
\hline MODIS & $\begin{array}{l}\text { Forest cover yearly composite maps, spatial and } \\
\text { temporal analysis maps of Ghana }\end{array}$ & $2000-2018$ \\
\hline NOAA AVHRR & $\begin{array}{l}\text { Forest cover yearly composite maps, spatial and } \\
\text { temporal analysis maps of Ghana }\end{array}$ & $1981-2018$ \\
\hline
\end{tabular}

\section{Image Pre-processing}

After image compositing, filtering, clipping and cloud sorting, a true color yearly composite of Ghana was produced for MODIS, Landsat and NOAA AVHRR.As shown in Fig.3, a median satellite composite that has been clipped to the boundary of Ghana with clouds in earth engine. After cloud sorting, the cloud cover in the composite was reduced to less than $5 \%$ as shown in Fig 4. 


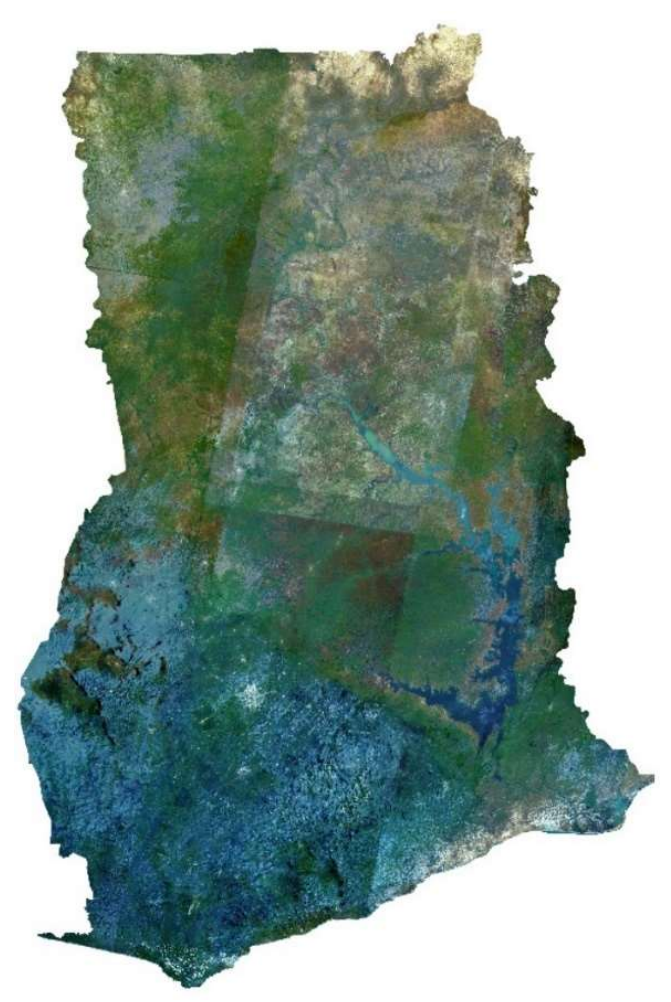

Figure 3.Before

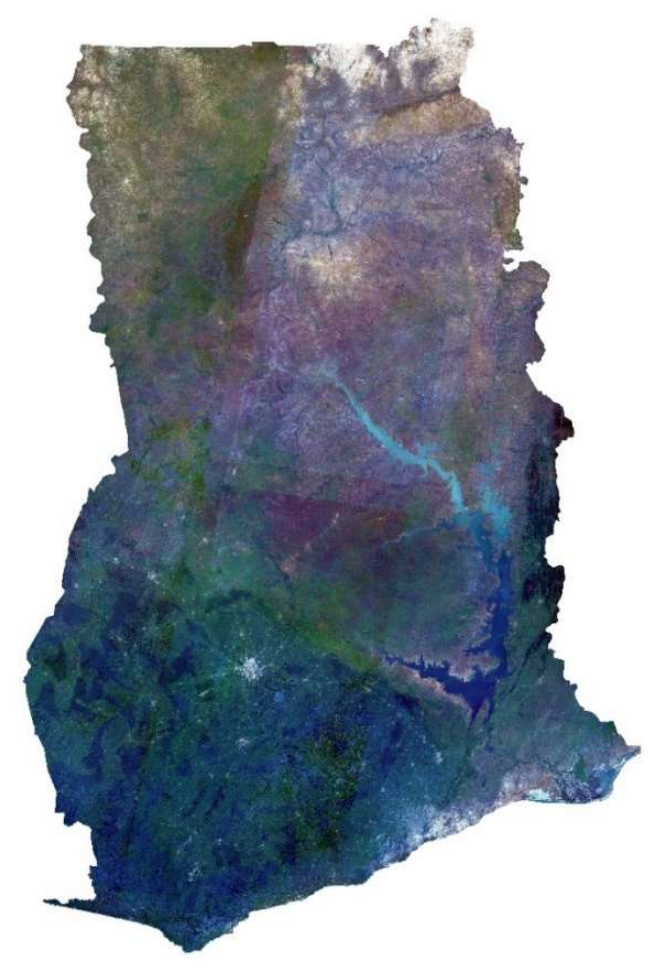


Figure 4.After

\section{Classification}

Unsupervised classification

After an engineered code for unsupervised classification was executed on the Google earth engine API using k-means with six clusters, a yearly classified image was produced indicating six different clusters This is the result of an unsupervised classification using K-means algorithm performed on a Landsat image composite with six clusters clipped to the boundary of Ghana on Google earth engine.

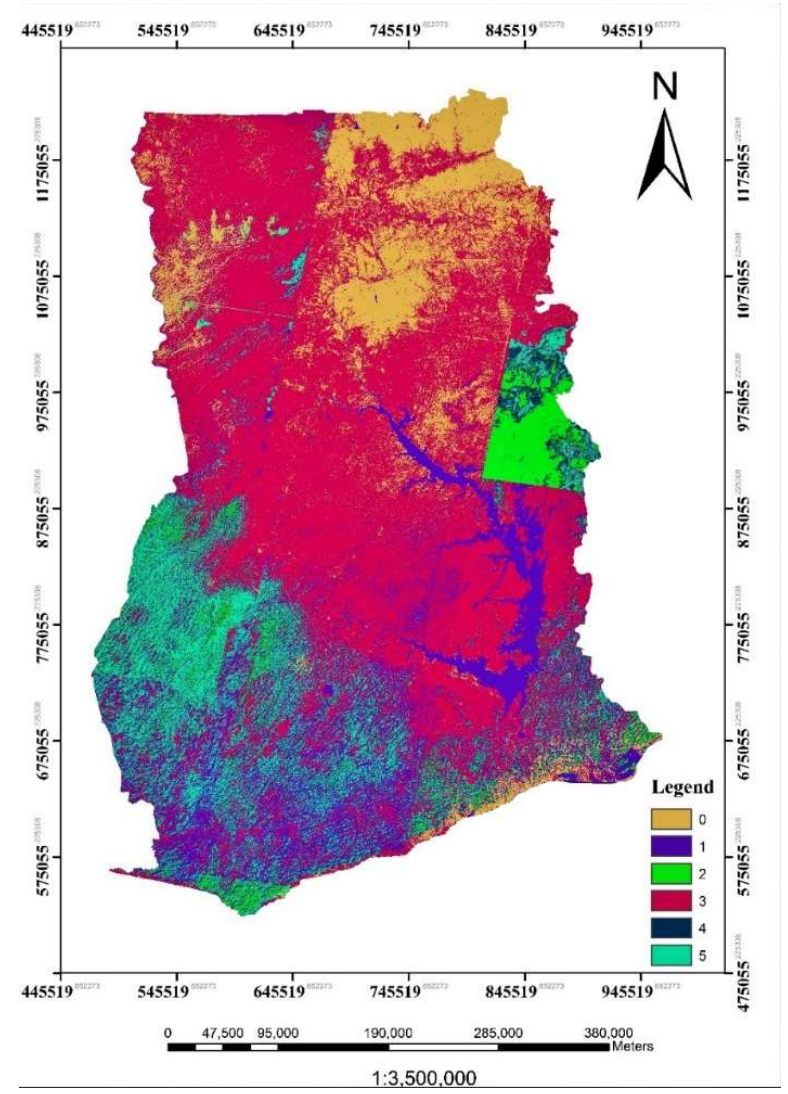

Figure 5.Unsupervised classification (K-means)

Supervised classification

Random Forest algorithm was used to classify the yearly composites using the yearly unsupervised classified images as thematic layer. Eight classes were used of which two classes had similar pixels. As a result of this grass and savannah were merged together 
to form one class, settlements and bare lands were also merged together to form one class. In total, six classes were used; Open Forest, Closed forest, Settlement and bare land, Cropland, Water, Grass and Savannah as shown in Fig.6 to produce a yearly supervised image for MODIS, Landsat and NOAA AVHRR.

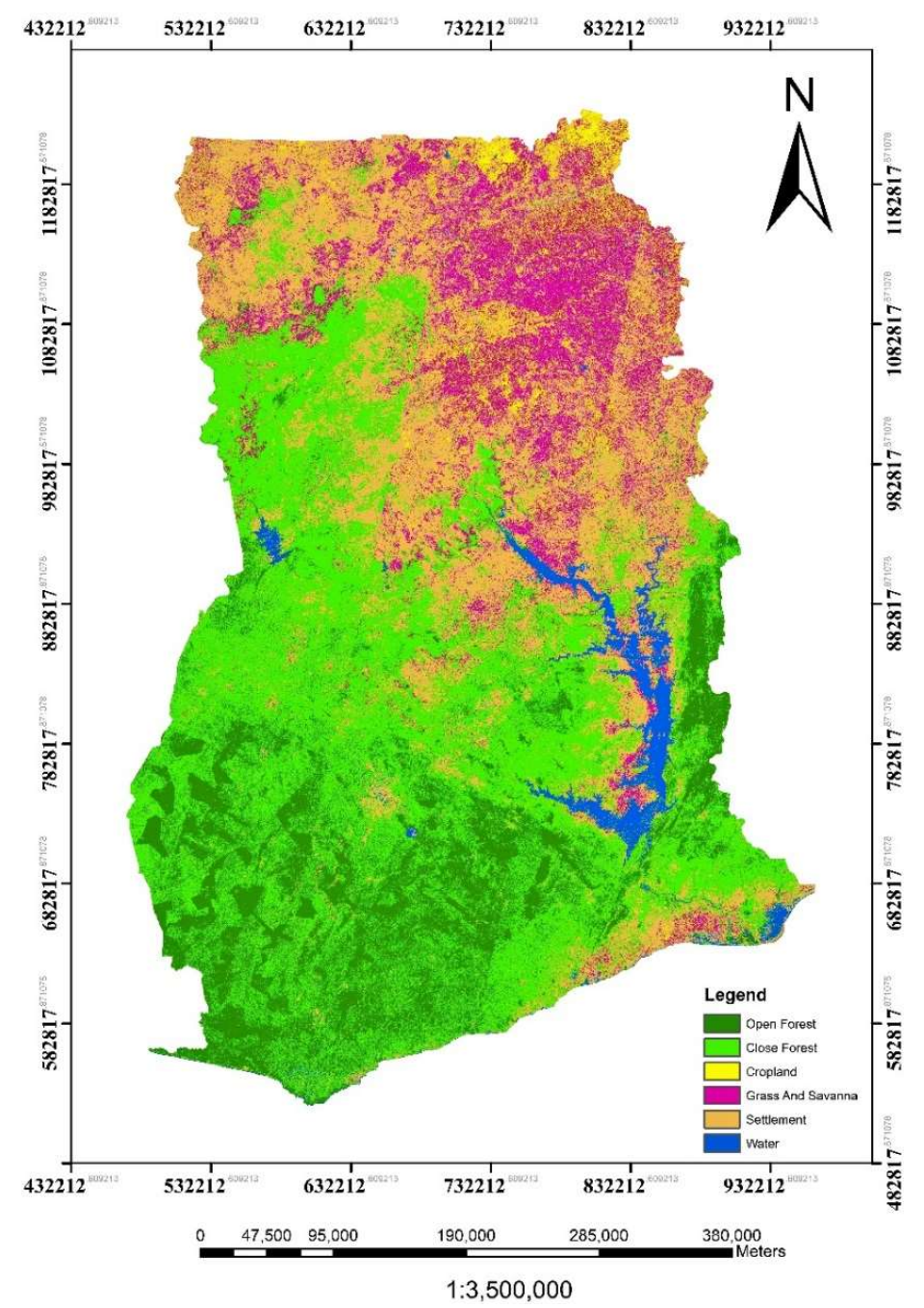

Figure 6.Supervised classification

Validation

After Random Forest supervised and K-means unsupervised classification, 70\% of the training data was able to produce an overall accuracy of $93 \%$ as shown in Table with error matrix. $30 \%$ of the training data was able to produce overall accuracy of $74 \%$ after error matrix computation on the Google earth engine platform using a built-in kappa and overall accuracy formula in JavaScript. 
Table 2. Accuracy Assessment

\begin{tabular}{|l|l|}
\hline Validation Error Matrix & $\begin{array}{l}\text { Training Confusion Matrix } \\
0:[215,1,8,0,14,1,43,0,0]\end{array}$ \\
1: $[8,6,0,0,4,0,6,0,0]$ & $1:[1,19,0,0,0,0,1,0,0]$ \\
2: $[2,0,1632,0,117,19,196,0,0]$ & $2:[0,0,1863,0,19,1,39,0,0]$ \\
3: $[0,0,0,0,0,0,0,0,0]$ & $3:[0,0,0,0,0,0,0,0,0]$ \\
4: $[8,1,193,0,1882,9,605,0,0]$ & $4:[3,0,47,0,2552,0,130,0,0]$ \\
5: $[2,0,145,0,69,182,183,0,0]$ & $5:[1,0,55,0,30,464,55,0,0]$ \\
6: $[18,0,294,0,573,36,3494,0,3]$ & $6:[9,0,75,0,151,2,4187,0,1]$ \\
7: $[7,0,1,0,1,0,5,4,0]$ & $7:[3,0,0,0,2,0,1,15,0]$ \\
$8:[4,0,2,0,2,2,18,1,18]$ & $8:[1,1,1,0,3,0,14,1,39]$ \\
Validation overall accuracy: $74 \%$ & Training overall accuracy: $93 \%$ \\
\hline
\end{tabular}

\section{Spatial and Temporal Analysis}

A spatial and temporal Analysis produced a 5-year composite maps of Ghana from 1981 to 2018 identifying the changes in the forest cover as time elapses. A positive result that can be computed over at any time on the Google earth engine API.After Supervised classification, the counts for the various classes were obtained as shown in the table below. These counts were used to compute for the forest counts in the various forest and game reserves and how forest cover is changing with time in Ghana.

Table 3. Class pixel Counts

\begin{tabular}{|c|c|c|c|c|c|c|c|c|}
\hline Landsat & $\begin{array}{l}1985 \\
\text { count }\end{array}$ & $\begin{array}{l}1990 \\
\text { count }\end{array}$ & $\begin{array}{l}1995 \\
\text { count }\end{array}$ & $\begin{array}{l}2000 \\
\text { count }\end{array}$ & $\begin{array}{l}2005 \\
\text { count }\end{array}$ & $\begin{array}{l}2010 \\
\text { count }\end{array}$ & $\begin{array}{l}2015 \\
\text { count }\end{array}$ & $\begin{array}{l}2018 \\
\text { count }\end{array}$ \\
\hline Open Forest & & & & 8783673 & 6873568 & 7229618 & 8837079 & 8332133 \\
\hline Close Forest & & & & $\begin{array}{l}1642925 \\
9\end{array}$ & $\begin{array}{l}2093917 \\
4\end{array}$ & $\begin{array}{l}2108279 \\
1\end{array}$ & $\begin{array}{l}2059306 \\
4\end{array}$ & $\begin{array}{l}1723542 \\
9\end{array}$ \\
\hline Cropland & & & & 1631025 & 3740536 & 2006754 & 2386872 & 1370541 \\
\hline
\end{tabular}




\begin{tabular}{|c|c|c|c|c|c|c|c|c|}
\hline $\begin{array}{l}\text { Grass and } \\
\text { savannah }\end{array}$ & & & & 8002799 & 5674259 & 6065210 & 9633802 & 4758385 \\
\hline $\begin{array}{l}\text { Settlement and } \\
\text { Bare land }\end{array}$ & & & & $\begin{array}{l}1110643 \\
2\end{array}$ & 8825520 & 9489724 & 4491546 & $\begin{array}{l}1436313 \\
9\end{array}$ \\
\hline Water & & & & 1329748 & 1229879 & 1408839 & 1340573 & 1223309 \\
\hline \multicolumn{9}{|l|}{ Modis } \\
\hline Open Forest & & & & $\begin{array}{l}2138235 \\
9\end{array}$ & $\begin{array}{l}1486303 \\
2\end{array}$ & $\begin{array}{l}1592263 \\
2\end{array}$ & $\begin{array}{l}1592263 \\
2\end{array}$ & $\begin{array}{l}1522525 \\
4\end{array}$ \\
\hline Close Forest & & & & 8049743 & $\begin{array}{l}1065349 \\
1\end{array}$ & $\begin{array}{l}1684462 \\
6\end{array}$ & $\begin{array}{l}1684462 \\
6\end{array}$ & $\begin{array}{l}1117892 \\
4\end{array}$ \\
\hline Cropland & & & & 2758027 & 3464518 & 1692542 & 1692542 & 1673768 \\
\hline $\begin{array}{l}\text { Grass and } \\
\text { savannah }\end{array}$ & & & & $\begin{array}{l}1067356 \\
5\end{array}$ & $\begin{array}{l}1292636 \\
7\end{array}$ & 9737255 & 9737255 & 9421156 \\
\hline $\begin{array}{l}\text { Settlement and } \\
\text { Bare land }\end{array}$ & & & & 3026770 & 3912601 & 1543674 & 1543674 & 8510177 \\
\hline Water & & & & 1392472 & 1462927 & 1542207 & 1542207 & 1273657 \\
\hline \multicolumn{9}{|l|}{ NOAA AVHRR } \\
\hline Open Forest & $\begin{array}{l}1031314 \\
5\end{array}$ & $\begin{array}{l}1045942 \\
0\end{array}$ & $\begin{array}{l}1405462 \\
4\end{array}$ & $\begin{array}{l}1105172 \\
4\end{array}$ & 9041633 & $\begin{array}{l}1008098 \\
6\end{array}$ & $\begin{array}{l}1041347 \\
5\end{array}$ & $\begin{array}{l}1072926 \\
2\end{array}$ \\
\hline Close Forest & $\begin{array}{l}1907582 \\
2\end{array}$ & $\begin{array}{l}1806788 \\
8\end{array}$ & $\begin{array}{l}1635807 \\
6\end{array}$ & $\begin{array}{l}1776898 \\
5\end{array}$ & $\begin{array}{l}1962328 \\
1\end{array}$ & $\begin{array}{l}2101740 \\
9\end{array}$ & $\begin{array}{l}1869348 \\
6\end{array}$ & $\begin{array}{l}1941170 \\
0\end{array}$ \\
\hline Cropland & 130455 & 265523 & 318278 & 604753 & 350985 & 407781 & 328745 & 1129707 \\
\hline $\begin{array}{ll}\text { Grass } & \text { and } \\
\text { savannah } & \end{array}$ & $\begin{array}{l}1488775 \\
0\end{array}$ & $\begin{array}{l}1526499 \\
5\end{array}$ & $\begin{array}{l}1334944 \\
5\end{array}$ & $\begin{array}{l}1528787 \\
8\end{array}$ & $\begin{array}{l}1561865 \\
2\end{array}$ & $\begin{array}{l}1274050 \\
6\end{array}$ & $\begin{array}{l}1535997 \\
6\end{array}$ & $\begin{array}{l}1405989 \\
1\end{array}$ \\
\hline $\begin{array}{l}\text { Settlement and } \\
\text { Bare land }\end{array}$ & 1543868 & 1699850 & 1795095 & 1493092 & 1692683 & 1627405 & 1411586 & 1597326 \\
\hline Water & 1331896 & 1525260 & 1407418 & 1076504 & 955702 & 1408849 & 1075668 & 355050 \\
\hline
\end{tabular}

Table 4. Percentage Gain and Loss table

\begin{tabular}{|l|l|l|l|}
\hline Satellite Mission & Forest Gain (\%) & Forest Loss (\%) & Range \\
\hline Landsat & 50 & 61 & $2000-2018$ \\
\hline Modis & 26 & 47 & $2000-2018$ \\
\hline NOAA AVHRR & 82 & 66 & $1985-2018$ \\
\hline NOAA AVHRR & 55 & 34 & $2000-2018$ \\
\hline
\end{tabular}


The difference between two datasets with 5years interval was executed to produce forest cover change composites of MODIS, Landsat and NOAA AVHRR. The composite was reclassified assigning digital number of 1 for gain with green palette, 0 for no change with yellow palette and -1 for loss with red palette as shown in Fig.7.

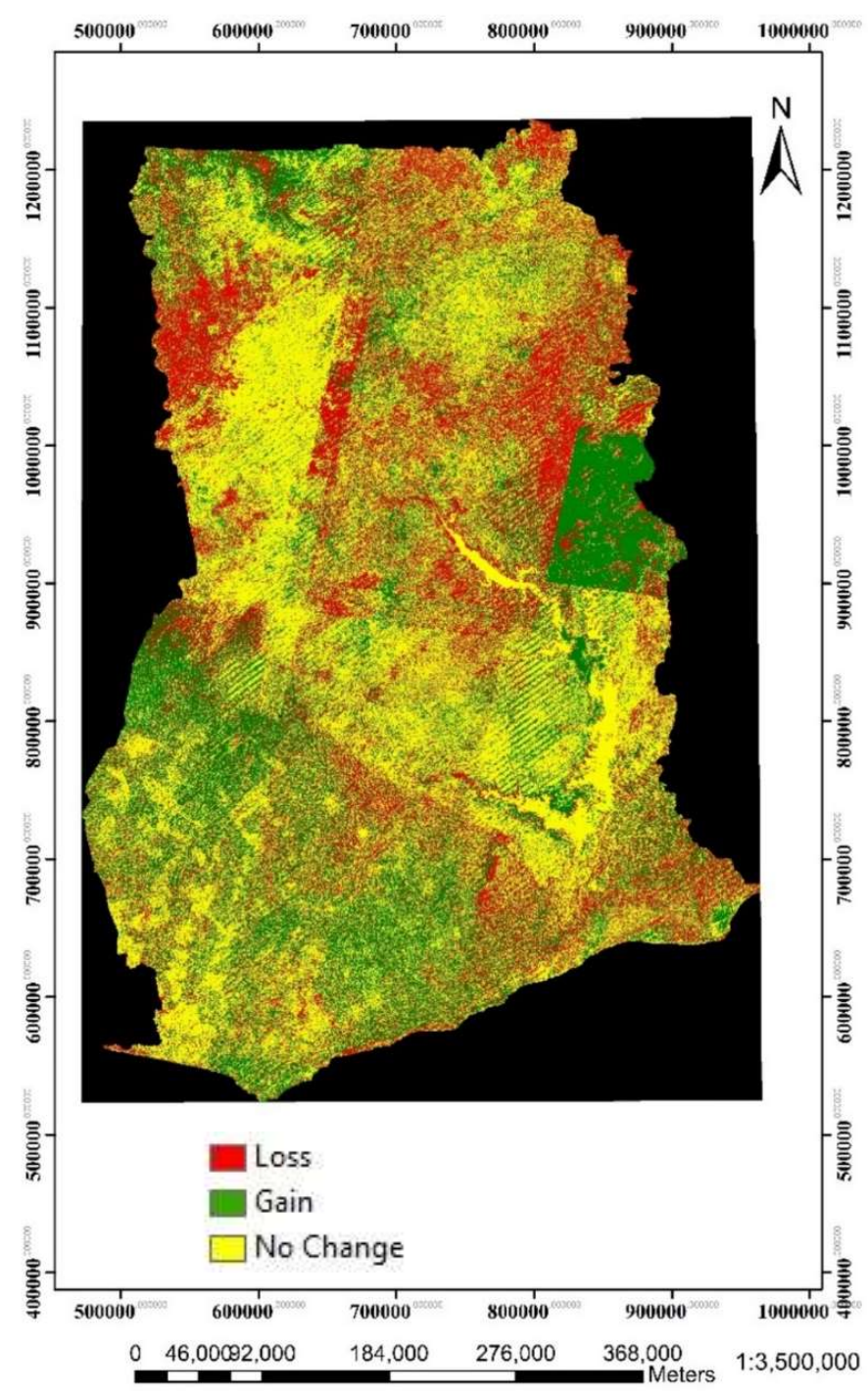

Figure 7.Loss and Gain

\section{Conclusion and Recommendation}

At the end of the project, a Google Earth Engine long term forest cover monitoring system with yearly composites and classified maps was produced for Ghana to investigate spatial and temporal patterns in forest cover. This project would be very useful in monitoring forest and game reserves in Ghana in aspects of determining the country's 
forest gains and losses as years go by. The project is powered by the Google Earth Engine to query and execute the processes without errors. The project produced yearly composite maps of Landsat, Modis and NOAA AVHR images of Ghana (AVHRR images for 1981 to 2018 analysis and Landsat and MODIS for 2000 to 2018 analysis) on Earth Engine platform. Classified maps of forest cover in Ghana were also produced followed by spatial and temporal analysis on the forest and game reserves. Landsat recorded $61 \%$ as total percentage count of loss and $51 \%$ as total percentage count of gain in the forest and games reserves from 2000 to 2018 . Modis recorded $47 \%$ as total percentage count of loss and $26 \%$ as total percentage count of gains in the forest and games reserves from 2000 to 2018. NOAA AVHRR recorded 34\% as total percentage count of losses and 55\% as total percentage count of gains in the forest and games reserves from 2000 to 2018.Landsat, NOAA AVHRR and MODIS composites were ranked in descending order of precision and accuracy for forest monitoring in Ghana. The yearly classified composites have also been made to investigate the spatial and temporal patterns in the forest cover of Ghana anytime new satellite images are recorded on the Google Earth engine platform and is capable of updating itself yearly.

As a result of technological advancements, there is a need for the country to involve the use of Google Earth Engine for forest monitoring since it is one of the applications best known for processing huge satellite data in Remote Sensing. This research has produced composites that will be relevant for land use land cover mapping and management in the country. Updated Datasets about forest has to be available for validation, correction and updating Ghana's forest dataset.

\section{REFERENCES}

Atlas, G. F. (2017). Global Forest Atlas, 1-2. Retrieved from http://globalforestatlas.yale.edu/temperate-zone Breiman, L. (2001). RANDOM FORESTS. Remote Sensing, 1-33. https://doi.org/10.1017/CBO9781107415324.004

Corresponding, D. L., Mausel, P., Brondízio, E., \& Moran, E. (2016). Change detection techniques. International Journal of Remote Sensing, 1161(October), 43. https://doi.org/10.1080/0143116031000139863

Debreuve, E., \& Morpheme, T. (n.d.). An introduction to random forests.

Desclée, B., Bogaert, P., \& Defourny, P. (2006). Forest change detection by statistical object-based method, $102,1-11$. https://doi.org/10.1016/j.rse.2006.01.013

Dr. Andrew Steer(World Resources Institute). (2017). earthengine. Retrieved 20 February 2017, from earthengine.google.com

Elith, J., \& Leathwick, J. R. (2009). Species Distribution Models: Ecological Explanation and Prediction Across Space and Time. Annual Review of Ecology, Evolution, and Systematics, 40(1), 677-697. https://doi.org/10.1146/annurev.ecolsys.110308.120159

Engine, E. (2017). Compositing , Masking, and Mosaicking Compositing with Reducers. Retrieved from https://developers.google.com/earth-engine 
Envoronment program. (2010). Retrieved 20 February 2018, from https://www.unenvironment.org

Forkuo, E. K., \& Frimpong, A. (2012). Analysis of Forest Cover Change Detection. International Journal of Remote Sensing Applications, 2(December), 82-92. Retrieved from Aeforkuo.soe@knust.edu.gh, Adb4gh@yahoo.com Abstract

GNA. (2017, July 28). Forestry Commission launches forest 2020 project. Retrieved from http://www.ghananewsagency.org/science/forestry-commission-launches-forests-2020-project-120211

Gorelick, N. (2012). Google Earth Engine WORKSHOP ON BIOMASS ESTIMATION AND MAPPING. AGU Fall Meeting Abstracts (Vol. 15). Retrieved from https://earthengine.google.com/

Hansen, M. C., Potapov, P. V, Moore, R., Hancher, M., Turubanova, S. A., \& Tyukavina, A. (2013). High-Resolution Global Maps of 21st-Century Forest Cover Change, 134(November), 850-854. https://doi.org/10.1126/science.1244693

Hansen, T., \& Forest, G. (2017). Introduction to Hansen et al . Global Forest Change Data. Retrieved 10 March 2017, from https://earthengine.google.com/

Horning, N. (2010). Random Forests: An algorithm for image classification and generation of continuous fields data sets.

Kennedy, R. E., Townsend, P. A., Gross, J. E., Bolstad, P., Adams, P., \& Cohen, W. B. (2009). Remote sensing change detection tools for natural resource managers: Understanding concepts and tradeoffs in the design of landscape monitoring projects, 113, 1382-1396. https://doi.org/10.1016//

Li, L., Zou, B., Hu, Q., Wu, X., \& Yu, D. (2013). Dynamic classifier ensemble using classification confidence. Neurocomputing, 99, 581-591. https://doi.org/10.1016/j.neucom.2012.07.026

Dietterich, T. G., 2002, Ensemble learning. The handbook of brain theory and neural networks, Edited by M. A. Arbib, The MIT Press, Cambridge: MA.

Pal, M., and Mather, P. M., 2003a, An assessment of the effectiveness of decision tree methods for land cover classification. Remote Sensing of Environment, 86, 554-565.

Friedl, M. A., Brodley, C. E., and Strahler, A. H., 1999, maximizing land cover classification accuracies produced by decision tree at continental to global scales. IEEE Transactions on Geoscience and Remote Sensing, 37, 969-977.

Muchoney, D., Borak, J., Chi, H., Friedl, M., Gopal, S., Hodges, J., Morrow, N., and Strahler, A., 2000, Application of MODIS global supervised classification model to vegetation and land cover mapping of Central America. International Journal of Remote Sensing, 21, 1115- 1138.

Lin, C., Tsai, P., Lai, K., \& Chen, J. (2013). Images Using Information Cloning. IEEE TRANSACTIONS ON GEOSCIENCE AND REMOTE SENSING, 51(1), 232-241. https://doi.org/10.1109/TGRS.2012.2197682

Paneque-Gálvez, J., McCall, M. K., Napoletano, B. M., Wich, S. A., \& Koh, L. P. (2014). Small drones for communitybased forest monitoring: An assessment of their feasibility and potential in tropical areas. Forests, 5(6), $1481-1507$. https://doi.org/10.3390/f5061481

Ramachandra, T. V, \& Kumar, U. (2004). Geographic Resources Decision Support System for land use , land cover dynamics analysis, (September), 12-14. Retrieved from http://ces.iisc.ernet.in/energy/Welcome.html

Ri, O., Xvlqj, P., \& Ojrulwkp, P. (2016). Unsupervised classification of remote sensing images using k-means algorithm. International Journal of Latest Trends in Engineering and Technology (IJLTET), 7(2), 548-552. https://doi.org/10.21172/1.72.584

Lillesand, T.M. and Kiefer, R.W. 2000. Remote sensing and image interpretation. John Wiley \& Sons, Inc., New York, NY, USA.

Schabrun, S. Case Studies (2017). https://doi.org/10.1007/978-1-4471-6750-1_8

Swaine, M. D. (2015). Classification and Ecology of Closed-Canopy Forest in Ghana. Journal of Ecology, 64(3), 913-951. Retrieved from http://www.jstor.org/stable/2258816

Blaschke. (2010). ISPRS journal of photogrammetry and remote sensing. Object Based Image Analysis for Remote Sensing, 65(1), 2-16. Retrieved from sciencedirect.com

Taylor, P., Jensen, J. R., Lulla, K., \& Jensen, J. R. (2008). Introductory digital image processing: A remote sensing perspective Introductory Digital Image Processing: A Remote Sensing Perspective. Geocarto International, (June 2012). Retrieved from http://dx.doi.org/10.1080/10106048709354084

Vittek, M., Brink, A., Donnay, F., Simonetti, D., \& Desclée, B. (2013). Land cover change monitoring using landsat MSS/TM satellite image data over west Africa between 1975 and 1990. Remote Sensing, 6(1), 658-676. https://doi.org/10.3390/rs6010658. 